\section{Wolves: Behavior, Ecology, and Conservation}

Edited by D. Mech and L. Boitani. 2003. University of Chicago Press, 5801 Ellis Avenue, Chicago, Illinois, 60637 USA. xvii +448 pages, U.S. $\$ 49$

In 1961, wolf biologist Douglas Pimlott wrote: "The wolf poses one of the most important conservation questions of our time. Will the species still exist when the twentieth century passes into history?"

Pimlott, if he were alive today, would be amazed and heartened by Wolves: Behavior, Ecology, and Conservation by L. D. Mech and L. Boitani because not only does it describe evidence of a "turn around" for the species that occurred in recent decades, but provides an encyclopaedia of scientific information about the wolf that has come from a remarkable amount of research over the past 40 years.

This book replaces one by David Mech written in 1970. However, this "update" is a much expanded, 22-authored, 448 page tome that provides one of the most extensive descriptions of the ecology of any mammal species in the world. The Table of Contents provides evidence of the book's depth, with chapters on: wolf social ecology; behaviour; communication; wolf-prey relations; wolf physiology; genetics; evolution and taxonomy; interactions with non-prey; restoration of the red wolf; wolves and humans; wolf conservation and recovery.

This is a book that you should read in selected chapters, rather than from cover to cover. There is too much detail to absorb, and although mostly written clearly, the style is fully referenced science. The book is well indexed, and brings together research conclusions on any conceivable topic related to wolves, very useful either for the interested person or the biologist.

The intent of the book, according to the editors, is to counter the "myth and legend, forklore and fairy tale" that has, and continues, to surround the species, by presenting a scientific view of the animal. The underlying assumption is that this scientific understanding will result in support for wise management of the expanded wolf populations that now exist in many places in the world. A more poetic reason for the book is given by physiologist Terry Kreeger: "Physiologically, we know a great deal about the wolf, although we still have much to learn. But why should we continue to study the wolf? Some people curse the animal; others deify it. As scientists study it, we may be able to blunt these extremes and place the wolf in proper perspective. Wolves tend to roughen the edges of a world being smoothed by human hands. For many of us, that is

\section{BOTANY}

\section{Rendezvous with the Wild: The Boreal Forest}

Edited by James Raffan, 2004. The Boston Mills Press, 132 Main Street, Erin, Ontario N0B 1T0 Canada. 192 pages, \$49.95 Cloth. good reason to learn what we can about them, inside and out, and certainly good reason to work for their conservation."

Some chapters are difficult, particularly those addressing wolf taxonomy and genetics, because the data from research are themselves confusing, contradictory or only tentative. Both fields have been fraught with "re-interpretations," sometimes by the same researchers, and consensus on what constitutes adequate evidence is unclear. For example, in the genetics chapter is a statement that parent-offspring relationships can be determined by examining nuclear DNA at as little as 10 microsatellite loci, whereas work done in association with our Algonquin wolf studies showed that as many as 15 loci were needed to avoid mistakes. These chapters leave their respective topics in chaos; hopefully, analytical methods soon will improve.

All other chapters are more readable and, because of the wealth of data, lead to more intruiging descriptions of the lives of wolves. Portrayed here are images of the wolf as a highly adaptable and intelligent species, one with a set of biological limits and norms, but with the flexibility to exercise a great deal of individual choice, the key to its success.

Human-wolf relationships are chronicled through the ages, right up to modern attitudes and their consequence for the future of the species. In a final chapter, Mech and Boitani reflect on the need to shift our perspectives on how to manage wolves from one of past "trench warfare" between people with different attitudes, to some new, more moderate paradigm that accepts the wolf with human imposed limits on population size, particularly in human-altered environments where it has been shown capable of surviving. Missing, however, is recognition of the importance of maintaining at least some areas as a crucible of natural selective forces surrounding the species - the very forces out of which the species evolved - rather than being content with the imposition of human modified environments and human control. There is still more to achieve before we congratulate ourselves in saving the real "wild" wolf in real intact wilderness.

\section{Literature Cited \\ Pimlott, D. H. 1961. Wolf control in Canada. Canadian Audubon Magazine, November-December, 2-9.}

JOHN B. THEBERGE

RR3, Site 25, Compartment 82, Oliver, British Columbia VOH 1 T0 Canada

Named after the Greek god of the northwind, Boreas, the boreal forests of the world carpet the northern circumpolar reaches. St retching across Canada from New- 